\section{Would e-cigarette regulation alone improve adolescents' health?}

I read with interest the $C M A J$ article on adolescent e-cigarette use. ${ }^{1}$

That study concluded that e-cigarette use among adolescents is a serious public health problem and that regulation is the best strategy to curtail increasing e-cigarette use by adolescents. However, a recent study from the Yale School of Public Health shows that this measure can have unintended and dangerous consequences. ${ }^{2}$ The results show that banning e-cigarette sales to minors actually increases their use of conventional cigarettes. We may need to carefully rethink an e-cigarette regulation strategy.

I am an adolescent, and I strongly believe that adolescents are puzzled by the common-sense validity of a proposal for a stricter regulation to limit the availability of e-cigarettes. Further, I doubt that this strategy alone would be effective. Even though certain laws limit face-to-face sales of e-cigarettes to adolescents, there is much less oversight online. ${ }^{3,4}$ Although most websites say buyers must be at least 18 years old, I know that adolescents and underage buyers can successfully place orders online. Moreover, online sales and targeted marketing are pushing adolescents toward e-cigarette use. ${ }^{5}$

Comprehensive prevention programs targeting adolescents are urgently needed in Canada. They need to be launched with the collaboration of schools, school boards, school administrators, parents, caregivers and youth organizations.

Getting adolescents involved in this prevention program is crucial and the key to success. I urge CMAJ to take a leadership role in a Canada-wide comprehensive school prevention program. We could perhaps tailor e-cigarette prevention programs similar to the old combustible cigarette prevention education programs.
We need an effective social media campaign to enhance adolescents' knowledge about the ingredients in e-cigarettes, their potential adverse effects and the known health hazards of prolonged use and misuse. There also needs to be a strong public education and awareness campaign to counter common myths and misconceptions (e.g., like e-cigarettes are a therapeutic tool).

\section{Nilanga Bandara}

Burnaby North Secondary School, Burnaby, BC

\section{References}

1. Khoury M, Manlhiot C, Fan CP, et al. Reported electronic cigarette use among adolescents in the Niagara region of Ontario CMAJ 2016:188:794-800.

2. Friedman AS. How does electronic cigarette access affect adolescent smoking? J Health Econ 2015; 44:300-8.

3. Williams RS, Derrick J, Phillips KJ. Cigarette sales to minors via the Internet: how the story has changed in the wake of federal regulation. Tob Control 2016 July 13 [Epub ahead of print]. doi:10.1136/tobaccocontrol-2015-052844

4 Williams RS, Derrick J, Ribisl KM. Electronic cigarette sales to minors via the Internet. JAMA Pediatr 2015;169:e1563

5. Soneji S, Gerling M, Yang J, et al. Online electronic cigarette marketing — violation of self-regulated standards by tobacco companies. JAMA Pediatr 2016;170:511-2

CMAJ 2016. DOI:10.1503/cmaj.1150126

\section{Well-placed advocacy}

Tyndall has provided a thoughtful commentary on hepatitis $\mathrm{C}$ treatment and is duly respectful of nonmedical determinants of health, which are heavy influences on hepatitis $\mathrm{C}$ epidemiology. ${ }^{1}$ As a physician providing frontline care for patients with this disease, I caution against presuming scarcity and approaching this problem with a treatment-or-prevention paradigm. We've applied this paradigm in the past with HIV and drug-resistant tuberculosis, only to find that treatment is actually a very good weapon in the prevention arsenal.

Although Tyndall does advocate for resources to be spent "upstream" at the level of prevention and addiction treatment, he does not recognize that finding a way to treat all cases of hepatitis $\mathrm{C}$ would be part of a complete prevention and harm reduction strategy. We must avoid the trap of assuming that we are slaves to limited resources, and instead continually seek innovative ways to provide our patients with the standard of care. As a service provider to Canada's most vulnerable people, who are already at an increased risk of suffering (poor, homeless, indigenous, women and children suffering from abuse, mentally ill), I am compelled to find ways to provide even better care than the standard to my patients.

Yes, the new hepatitis $C$ treatment regimens are expensive. Does that mean we should ration those treatments based on cost, or fight hard for a fairer price and good access for all? I am going to place my advocacy where it belongs: with the latter.

\section{Bonnie R. Larson MD}

Calgary Urban Project Society, Calgary, Alta.

\section{Reference}

1. Tyndall M. Misplaced advocacy: What does better hepatitis C treatment really mean? CMAJ 2015; 187:1111-2

CMAJ 2016. DOI:10.1503/cmaj.1150123

\section{What were incentive payments accomplishing?}

I read with interest the analysis of incentive payments to family physicians in British Columbia for treating patients with chronic disease.

The study's finding of no health care outcome changes supports my own observations: those of us who have chosen family practice as a career want to do a good job, regardless of whether there is an incentive payment attached.

It was no surprise that measures of patient outcomes have not changed. I believe that there was another valid reason for initiating incentive payments to support full-service family practice as a whole. The main change I have witnessed has been in the career choices made by new graduates since the incentive programs have been fully opera- 